\title{
“MANDÓ PINTAR DOS AVES...": RELATOS ORALES Y REPRESENTACIONES VISUALES ANDINAS
}

\author{
"HE COMMANDED THAT TWO BIRDS BE PAINTED...": \\ ORAL STORIES AND ANDEAN VISUAL IMAGES
}

\author{
José Luis Martínez C. ${ }^{1}$
}

\begin{abstract}
Antes de la invasión europea a los Andes, existían ciertos temas o motivos de conocimiento colectivo, ya fueran míticos, de memoria, políticos u otros, que podían circular y ser transmitidos en distintos soportes, ya fueran visuales, orales o dramatizados. Se propone que un mismo relato o un mismo ciclo, por ejemplo, la expansión del Tawantinsuyu, pudo ser representado simultáneamente en diferentes soportes, cada uno a partir de sus propias lógicas constructivas y de sus propias sintaxis. Este tipo de prácticas habría servido, igualmente, para hacer circular más tarde otras narrativas andinas, ya coloniales, como el ciclo de la muerte del Inca Atahualpa.
\end{abstract}

Palabras claves: arte rupestre, sistemas visuales, oralidad, incas, período Colonial.

Before Spanish invasion of the Andes, there existed major themes or motifs of collective knowledge about myths, politics, memory, and other topics, that could circulate and be transmitted in distinct media, such as oral, visual or dramatic representations. I propose that a particular story or cycle, for example, the expansion of Tawantinsuyu, could have been represented simultaneously in different media, each of them with its own logic and syntaxis. This type of practice could equally have served later to circulate other Andean narratives, such as narrative cycle of Inca Atahualpa's death.

Key words: Rock art, visual systems, oral records, Incas, Colonial Period.

Uno de los aportes de John Murra que me parece relevante, entre tantos otros que pueden ser destacados, es su interés por entender cómo siguieron funcionando las sociedades andinas después del choque colonizador. En varios de sus trabajos es posible advertir muestras de ese interés (como cuando destacaba la carta que los señores andinos, reunidos en la localidad de Mama, le enviaron al rey de España) ${ }^{1}$. Un artículo demostrativo de lo mismo es, me parece, el que escribió sobre la correspondencia entre un capitán de mita y su apoderado potosino, a inicios del siglo XVII ${ }^{2}$. La figura de Diego Chambilla es sumamente interesante, ya que, como lo destacó Murra, la base para el activo comercio que desarrollaba bajo las lógicas del mercado colonial descansaba en la articulación entre su cargo de señor étnico de los lupacas y el manejo de viejas lógicas andinas, como la mantención de tierras de cultivo, dispersas en una amplia franja entre el lago Titicaca y el Océano Pacífico.

Lo que me parece medular en la perspectiva de Murra es el intento de rescatar, precisamente, esas complejidades y rastrear cómo algunas lógicas andinas resultaban eficientes, aun en los nuevos contextos coloniales. Creo que esta mirada puede ser de gran ayuda para entender también otras prácticas coloniales, aunque ellas funcionaran en campos distintos a los que usualmente abordó John Murra.

\section{Mandó Pintar...}

Según Garcilaso, al menos hasta finales del siglo XVI era posible ver, en una altísima peña ubicada en un paraje en las cercanías de la ciudad del Cusco, una pintura que representaba dos cóndores y que el Inca Huiracocha mandó pintar después de la derrota de los chancas en el sitio al Cusco. Uno de los cóndores que, con las alas cerradas y la cabeza baja, en actitud de huida, miraba hacia el Collasuyu dándole las espaldas al Cusco, representaría la actitud y cobardía del Inca Yahuar Huaca ante la amenaza de la invasión de los chancas; el otro, vuelto hacia la ciudad, aparecía "feroz, con las alas abiertas, como que iba volando a hacer alguna presa" (Garcilaso 1991[1609]: Capítulo XXIII, p. 306), representando a

$1 \quad$ Universidad de Chile, Centro de Estudios Culturales Latinoamericanos, Casilla 73, sucursal Grecia, Santiago, Chile. jomarcer@u.uchile.cl 
Huiracocha Inca acudiendo con rapidez a la defensa de la capital incaica.

Independientemente de quienes fueran los personajes representados (Garcilaso es el único que atribuye estos episodios a Yahuar Huaca y Huiracocha y no a Huiracocha y Pachacuti Inca), se trataría de una pintura que plantea la existencia de varias posibles relaciones. En primer lugar, y en una lectura tal vez demasiado directa, entre un supuesto "hecho": el de la guerra entre incas y chancas y la defensa de la ciudad del Cusco, por un lado, y una pintura rupestre de carácter conmemorativo y con contenidos ético-políticos, por el otro. Habría, en este plano, la posibilidad de varias lecturas: una, la de la estructura superficial del relato visual: "el hecho representado"; otra, posiblemente a nivel de estructuras profundas, la de las jerarquías espaciales y otras categorías ordenadoras, sugerida por las posiciones y direcciones de ambas aves; una tercera, la de la memoria; finalmente otra, la valórica ${ }^{3}$.

En segundo lugar, está planteada una relación entre un conjunto de relatos pertenecientes a una narrativa -me refiero en este caso al ciclo ${ }^{4}$ de la guerra entre los incas y los chancas- que se desplegaban en el plano de la oralidad y posiblemente de una gestualidad, y una representación visual que aparentemente sintetizaba en dos imágenes principales (no sabemos qué otros elementos había en la pintura rupestre) algunos de los elementos que esa tradición narrativa consideraba centrales.

Antecedentes de posibles relaciones entre textos orales y visuales han sido descritos, asimismo, para otros conjuntos narrativos prehispánicos, como el del ciclo referido a Yakana, la constelación negra que en las tradiciones huarochiranas tenía la capacidad de asegurar la reproducción del ganado ${ }^{5}$. Al menos un conjunto de paneles con arte rupestre, ubicado en el río Loa (en el norte de Chile) pareciera dar cuenta, también de manera visual, de varios de los mismos componentes de ese ciclo (Berenguer y Martínez 1989). Si la interpretación es correcta, allí se habrían representado, entre otras figuras, la de un camélido en posición de amamantar a otro, más pequeño y en posición invertida (tal como aparece en los relatos recogidos sobre esa constelación específica), y la de una perdiz o Yutu, otra de las constelaciones negras mencionadas en el ciclo oral.

Estos ejemplos me parecen extremadamente importantes, porque ponen en evidencia que antes de la invasión europea a los Andes existían ciertos temas o motivos de conocimiento colectivo, ya fueran míticos, de memoria, políticos u otros, que podían circular y ser transmitidos en distintos soportes. Es ya sabido que en los Andes se utilizaron diferentes tipos de soportes para articular y/o producir mensajes o registrar informaciones determinadas. Los quipus, los queros, los textiles, los bailes, cierta geografía o algunas edificaciones o monumentos conmemorativos como las chullpas, entre otras, contenían información y permitían, por ejemplo, reactivar una memoria colectiva. Lo que no es tan evidente es el hecho de que un mismo relato, un mismo tema, por ejemplo, la expansión del Tawantinsuyu, pudiera ser representado simultáneamente en diferentes soportes, cada uno a partir de sus propias lógicas constructivas y de sus propias sintaxis.

A pocos años de iniciada la dominación colonial española, en la misma ciudad del Cusco durante la celebración de la fiesta del Corpus Christi de 1555, uno de los participantes, cacique de los cañaris y aliado de los españoles contra Manco Inca, hizo pintar en sus andas unas pinturas, señalándole a los espectadores europeos: "Estas cuatro pinturas de mis andas son cuatro batallas de indios y españoles en las cuales me hallé en servicio dellos" (Garcilaso 1962 [1617]:1085). Si bien no se trataba de un ciclo narrativo muy amplio, y probablemente la historia de los enfrentamientos entre los cañaris y las tropas de Manco quedó en el restringido círculo de sus participantes y en la memoria de algunos de sus descendientes, se trata del mismo tipo de relación entre un corpus narrativo y su representación visual, lo que pareciera formar parte de las prácticas comunicacionales andinas.

En todos los casos reseñados se trataba de sistemas visuales en los que aparentemente no se necesitaría de la presencia de un especialista que fuera capaz de leer ciertos signos inscritos en un soporte físico, para restituirlos o integrarlos a una lectura interpretativa mayor o para un público más amplio que de otra manera no habría podido decodificar las inscripciones, como pareciera ser el caso de la pintura de algunas tablas (como las del Poquen Cancha que contenían la historia incaica) ${ }^{6}$, o del sistema de varas sobre el que ha llamado la atención Salomon ${ }^{7}$, que registraba memorias dinásticas y sucesorias, permitiendo dirimir algunos pleitos, tal como lo señalaron don Diego Cayo, descendiente de Pachacuti Inca Yupanqui, y don Alonso Tito Atauchi, nieto de Huayna Cápac, al Virrey Toledo: 
...dijeron los dichos Don Diego Cayo y don Alonso Tito Atauche, que ellos vieron una tabla y quipos donde estaban sentadas las edades que hubieron los dichos Pachacuti Inga y Topa Inga Yupanqui su hijo, y Guayna Capac, hijo del dicho Topa Inga, y que por la dicha tabla y quipo vieron que vivió Pachacuti Inga Yupangui cien años, y Topa Ynga Yupangui hasta cincuenta y ocho o sesenta años y Guayna Capac hasta setenta años,... (Levillier 1940 Tomo II, Libro I:173).

En este tipo de sistema de registros, lo visual requería de la oralidad para ser interpretado, pero, al mismo tiempo, lo oral requería de lo visual para estructurar su relato. Unido a lo anterior, era necesaria la presencia de un especialista para poner en circulación el mensaje.

Me parece que las relaciones de significación y comunicación que estoy intentando destacar son diferentes igualmente a aquellas que habrían existido entre algunos queros grabados y textiles que, puestos en determinados contextos rituales, según Cummins (1993:122), también habrían permitido poner en juego temas políticos y de memoria de acontecimientos importantes para la historia incaica $^{8}$. En el caso que señala Cummins, se trataba de rituales en los que ambos objetos eran usados juntos para recordar, a través de su relación simbólica, algunos momentos o elementos de la historia incaica. De allí que pueda suponerse que, como en el caso anterior de las tablas y las varas, se trataba de sistemas mixtos o complejos, que requerían de una simultaneidad, de la presencia conjunta de dos o más soportes y probablemente de un especialista, sin los cuales no podrían entregar la información que conservaban en sus superficies.

Hay otro tipo de situaciones que también me parece importante diferenciar. Me refiero a que era frecuente que determinados signos o símbolos se representaran por doquier, pero aisladamente, en textiles o en las paredes de una chullpa, como lo han mostrado los trabajos de Gisbert (1999:18 y ss.), o Abercrombie (2006:242 y ss), o en paneles de pinturas rupestres ${ }^{9}$.

Por el contrario, los datos sobre el tipo de prácticas que señalé inicialmente sugieren, en primer lugar, que se trataba de soportes muchas veces expuestos públicamente para públicos amplios y que, por consiguiente, deberían permitir al menos un primer nivel de lectura o decodificación, cuyos códigos fueran social y ampliamente compartidos $\mathrm{o}$, por lo menos, que presentaran la posibilidad de ser sensiblemente percibidos aun para quienes no poseyeran todas las claves de su lectura o comprensión. En segundo lugar, me estoy refiriendo aquí a textos (orales, visuales u otros) que formaban parte de conjuntos narrativos mayores. Sabemos que el ciclo de la guerra contra los chancas tenía diferentes versiones y que unas enfatizaban a algunos personajes en detrimento de otros, o presentaban las secuencias con distinto orden ${ }^{10}$. Se trataba de una narrativa, de un verdadero ciclo. Si pueden ser tratados como conjuntos es porque es posible reconocer en unos y otros, a pesar de estas diferencias, elementos de un tema común. En tercer lugar, es evidente que al menos los conjuntos orales no requerían de los soportes visuales para ser narrados y actualizados ya fuera para los públicos andinos como, más tarde, para los cronistas, puesto que ninguno de ellos describe su uso cuando recogieron las versiones que hoy conocemos, por lo que se puede asumir un cierto grado de autonomía entre los diferentes tipos de soportes.

Hay otro sistema de representaciones del que no he hecho mención aún y que podría ayudar a entender mejor este tipo de prácticas para hacer circular un tema: me refiero a las dramatizaciones públicas. Los wanka, taqui, jarawi u otros parecen haber sido las formas más comunes de esas narrativas dramatizadas o, al menos, las más conocidas y descritas por algunos cronistas, efectuadas no sólo en el Cusco, sino también por muchos otros grupos locales.

Lamentablemente, los diccionarios coloniales no traducen la voz wanka, que ha sido entendida como un tipo de género, básicamente poético. López Baralt (1993:36 y ss.) la traduce como "elegía incaica" y uno de sus rasgos distintivos sería el de poseer una métrica formal, aunque no se dice nada acerca de si además incorporaba formas musicales o coreográficas que permitieran entenderla también como textos dramatizados. Tampoco sabemos acerca de los contenidos de estas elegías o si ellas formaban parte de conjuntos narrativos mayores.

En cambio, las referencias sobre los taqui y jarawi son más abundantes. Para dar cuenta de los mitos de origen de los ayllus de Huarochirí, los redactores andinos del texto escribieron: "Ahora vamos a describir las tradiciones de los Checa, el rito de los yungas llamado Machua y las danzas que 
los acompañaban y enseguida contaremos sobre el origen de los hombres" (RTH, Capítulo 24, en Taylor 1987; el énfasis es mío ). En este caso, el término quechua empleado por esos mismos redactores fue el de taqui, término que remite tanto al baile como al canto ("cantar solo sin baylar o cantando baylar"; González Holguín 1989 [1608]:332) y también a un tipo específico de coreografía: "yr muchos a la par a las parejas, o al lado vnos de otros, o en hila derechos, o en ala y no detrás" (González Holguín 1989 [1608]:332). Aparentemente los taqui eran también un tipo de baile y música vinculados a rituales del poder, ya sea recibiendo a los señores étnicos o acompañándolos en sus desplazamientos (Estenssoro 1992:355). Abercrombie (2006:239) ha destacado el carácter espacial y coreográfico que tenían los taqui, llamando la atención acerca de que implicaban un recorrido por senderos, literalmente de memoria, al hacer escalas y paradas en aquellos puntos o lugares considerados relevantes para las memorias locales o imperiales. Sin embargo, de las descripciones coloniales conocidas no resulta evidente la relación entre la letra y música de los taqui con los lugares de detención. No sabemos, por ejemplo, si una de ellas o ambas hacían referencia a otro texto narrativo, o si simplemente era el hito mismo el que permitía recordar y activar esa memoria. Nuevamente nos topamos aquí con la escasez de información. Las referencias coloniales más tempranas se restringen a sus formas (ya sea música, o baile, o ambos) o contextos (los vinculados a las autoridades andinas, a las divinidades $u$ otros) y no a sus temáticas.

De acuerdo al mismo González Holguín, aparentemente serían los jarawi las formas musicales que parecieran aproximarse más a lo que estoy buscando: "Haraui o yuyaycucuna o huaynaricuna taqui. Cantares de hechos de otros o memoria de los amados ausentes y de amor y afición y agora se a recibido por cantares devotos y espirituales" (González Holguín 1989 [1608]:152). Los sinónimos que propone el jesuita son extremadamente sugerentes. Uno de ellos es el de taqui, lo que permitiría suponer que los jarawi también incluían determinadas coreografías y movimientos, no solo la letra y música en sus cantares. El otro sinónimo de jarawi en esa definición es yuyai, término que remite a ciertos actos de memoria, tales como "acordarse, pensar y tener cuydado de algo, o tener cargo del": yuyani; o "Traer algo en la memoria": yuya yuyani, o yuyarayani; $\mathrm{y}$ "traer a la memoria alguna cosa": yuyarccuni, o yuyarimuni (González Holguín 1989 [1608]:372 y 373). Aquí sí, me parece, estaríamos en presencia de un soporte específico, el baile y la música y, tal vez, una cierta forma de dramatización o representación coreografiada, que comunicaban o retransmitían otro texto, una narrativa de los "hechos de otros" que probablemente también podía ser contada sin el auxilio de los jarawi.

Es este el tipo de relación que ando buscando, puesto que aquí se trataría de una forma dramatizada (musicalizada y coreografiada) que permitía "traer a la memoria" otros conjuntos narrativos, esos "cantares de hechos de otros", por ejemplo, que propone la definición. Si mi interpretación es correcta, los jarawi serían otro de los sistemas que proporcionaban distintos soportes a la circulación amplia de temas de memoria, políticos u otros como los que señalé inicialmente. Así, lo que también aparece es la gama relativamente amplia de soportes que participarían de ese sistema común: pinturas rupestres, textiles, queros, piezas dramáticas y relatos orales parecieran haber sido los más recurrentes.

\section{Rupturas y Transformaciones}

¿Qué pasó con estos sistemas en el período Colonial? ¿Qué ocurrió con estas formas de hacer circular socialmente una información? En su trabajo sobre las etnocategorías de un quipu estatal, Murra señalaba cómo ese sistema de registro "reflejó, desde muy temprano, las presiones foráneas sobre la economía andina" (Murra 2002:249). Lo que pone de relieve esta observación de Murra es que, contrariamente a lo que se ha planteado, algunos de los sistemas de registro o de comunicación fueron mucho más moldeables a los nuevos contextos sociopolíticos y culturales, mostrando una notable capacidad para incorporar nuevos temas y discursos, que daban cuenta desde una perspectiva andina (colonial por cierto) de las antiguas y más recientes preocupaciones de esa sociedad.

Es cierto que, como lo han señalado diversos estudiosos, con la represión desatada por los procesos de evangelización y de extirpación de idolatrías, muchos de los sistemas de registro y comunicación prehispánicos, en especial aquellos que requerían de los espacios públicos, tendieron a desaparecer ${ }^{11}$. Quisiera, sin embargo, sugerir que también se produjo una transformación en ellos y que la antigua práctica de presentar, registrar y comunicar un 
mismo tema a través de diversos soportes continuó en desarrollo, bajo nuevas modalidades o con nuevos temas, a veces acudiendo a soportes muy similares a los prehispánicos.

Durante parte del período Colonial siguió produciéndose este tipo de prácticas y de relaciones entre diferentes soportes vinculados a partir de la transmisión de una misma temática, con las obvias transformaciones y en los nuevos contextos que se produjeron a partir de la invasión europea. En efecto, es frecuente encontrar una relación entre algunos ciclos de las narrativas orales coloniales, ya sean cuzqueñas u otras más locales, con algunos textos visuales. Cabello (2006) ha destacado como, por ejemplo, un acontecimiento histórico específico ocurrido en el siglo XVI: el otorgamiento de un escudo a la ciudad de Trujillo fue aprovechado por un señor étnico local para presentar su propia versión del acontecimiento, destacando el relato del apoyo de los señores norteños a los españoles y su nueva posición política, a través de las imágenes visuales representadas en una pajcha, un recipiente ritual de madera, que al igual que los queros coloniales, incorporó escenas figurativas en algunos de sus campos de diseño. En el caso concreto al que me refiero, se representó un grupo de soldados españoles rindiendo armas a un gran felino central con atributos prehispánicos (Figura 1), el que sería una representación metafórica -como en el caso de la pintura de los cóndores cuzqueños-de un personaje principal, probablemente don Martín Cajacimcim o Sachas Guamán (Cabello 2006:167).

Donde las relaciones entre conjuntos de narrativa oral y textos visuales coloniales son más evidentes, es en los queros pintados. Tal como lo han señalado diversos autores (Chávez Ballón 1964:28; Cummins 1998, 2004; Flores Ochoa et al. 1998; Gisbert 1999:94-95; Sandrón 1999), es posible identificar vínculos temáticos entre algunas de las escenas figurativas representadas en el campo superior de muchos de los queros pintados coloniales, con sus respectivos conjuntos de relatos, ya se trate de ciclos míticos, como la fundación del Cusco por Manco Cápac y Mama Ocllo (Flores Ochoa et al. 1998:167), o de narrativas sobre la expansión cuzqueña, como la expansión hacia el Antisuyu (Figura 2), o la derrota de los señores collas. En este caso, algunas transformaciones coloniales parecen hacerse evidentes, puesto que las escenas que se pintaron en los queros apelaron a un lenguaje visual figurativo y ya no abstracto como era lo usual antes de la caída del Tawantinsuyu. Los queros coloniales, sin embargo, conservan en algunos de sus campos (generalmente en el central) al menos una banda con figuras abstractas, básicamente compuestas por tocapus o figuras geométricas (Figura 3), que aluden a la posible mantención de otro tipo de lenguajes visuales coexistiendo con el representativo, de origen colonial y con influencias europeas ${ }^{12}$.

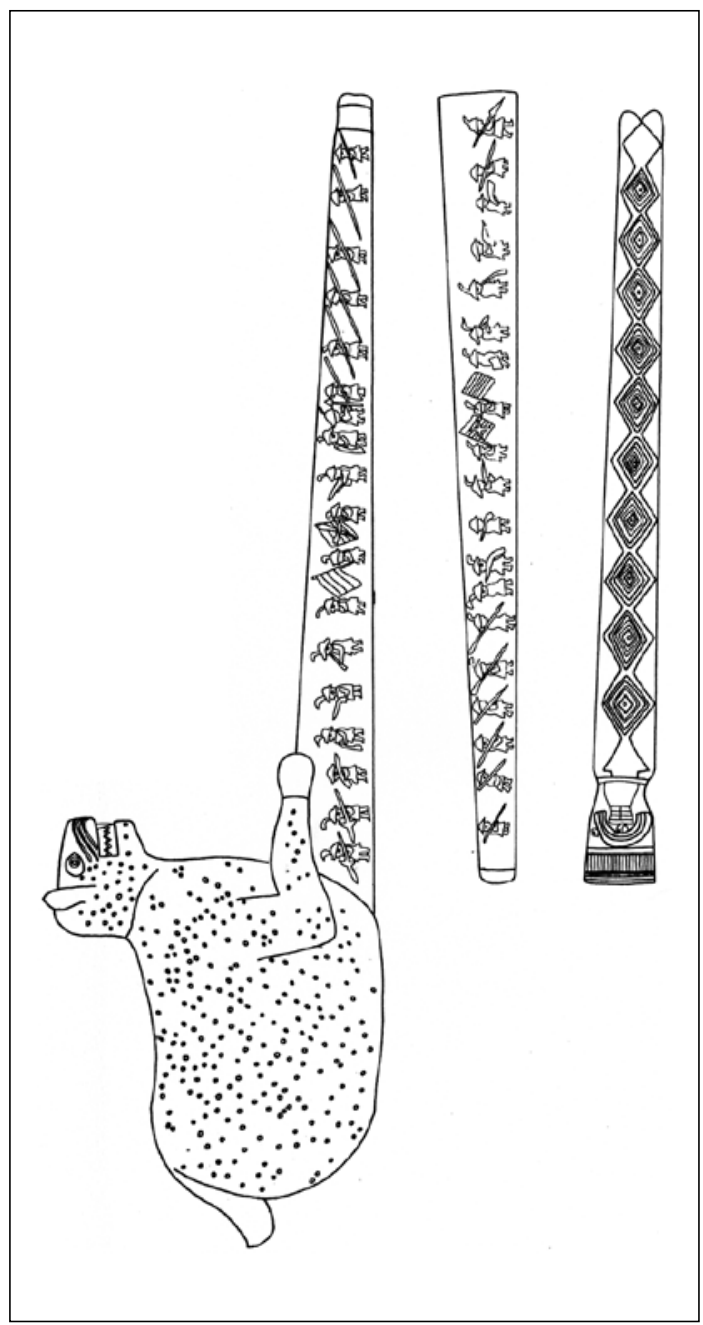

Figura 1. A ambos lados del tubo de esta pajcha ceremonial de madera están representadas escenas de un desfile militar español que rinde honores al felino que domina toda la pieza. Pajcha MAM 7569, perteneciente al Museo de América (Madrid). Dibujo del Museo de América.

On both sides of the tube of this ceremonial pajcha, there are scenes representing a military parade of Spanish soldiers saluting a feline that dominates the piece. Pajcha MAM 7569, Museo de América collection, drawing by Museo de América, Madrid. 


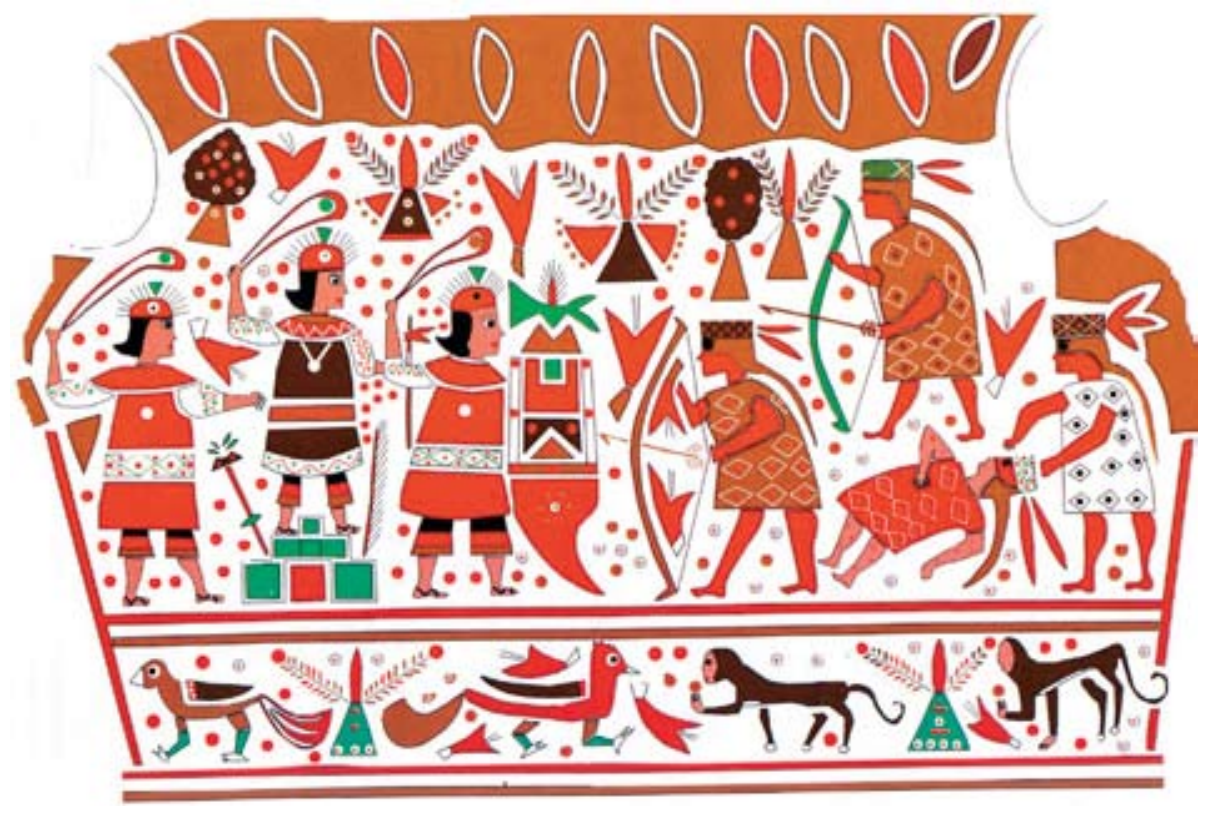

Figura 2. kero colonial, vaso de madera ceremonial con un motivo del ciclo de la expansión del Tawantinsuyu. Representa una escena de enfrentamiento entre guerreros cusqueños y antis. Kero VA 368, perteneciente a la colección del Museum für Völkerkunde (Berlin), en Wichrowska y Ziólkowski (2000:115).

Colonial kero, ceremonial wooden cup with a motif of the Tawantinsuyu expansion cycle. It represents a scene of a battle between warriors from Cuzco and Anti. Kero VA 368, Museum für Völkerkunde collection (Berlin), in Wichrowska \& Ziólkowski (2000:115).

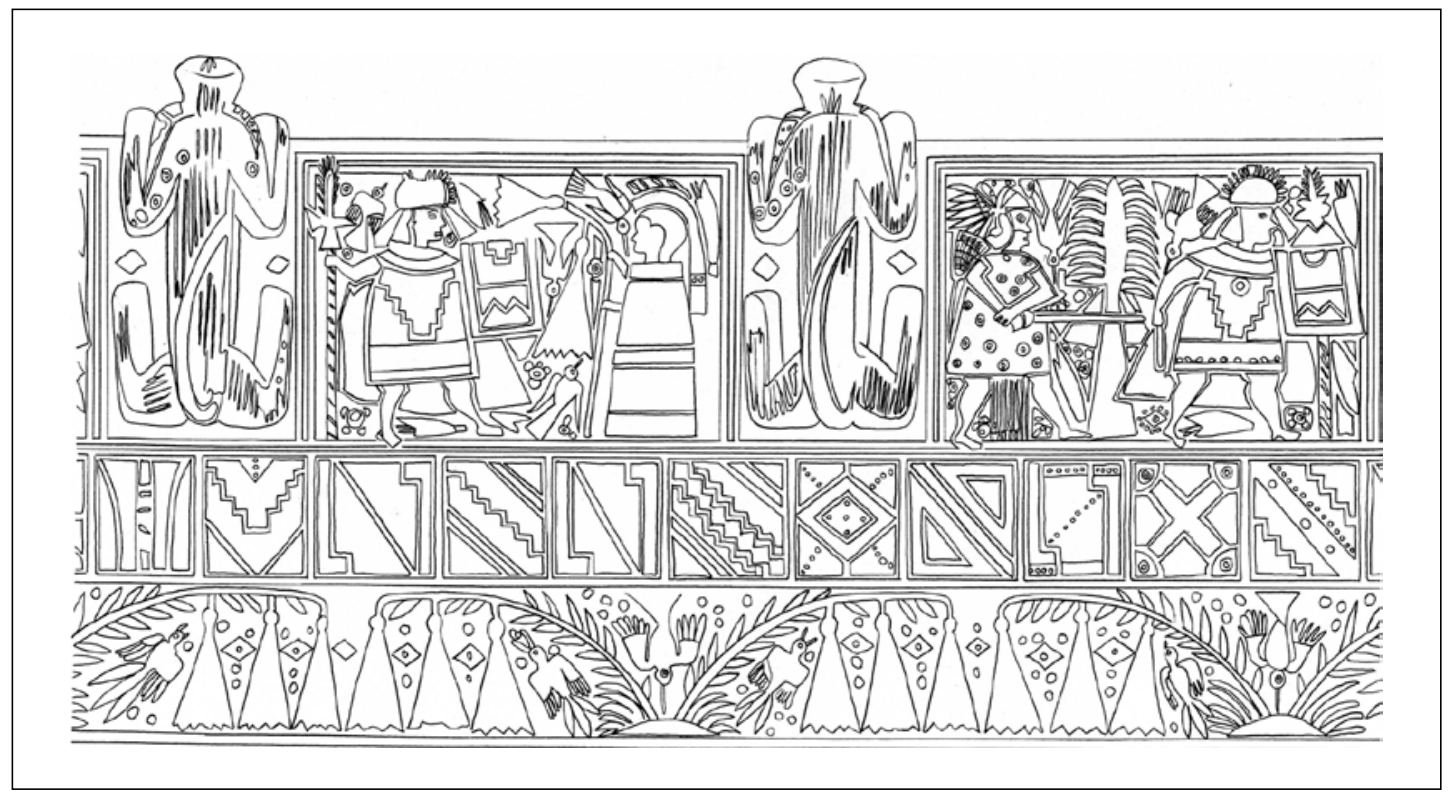

Figura 3. Kero colonial con banda central de tocapus. Kero Momac 164, perteneciente al Museo Inka (Cusco). Dibujo de Clara Yáñez. Colonial kero with central band of tocapus. Kero Momac 164, Museo Inka collection (Cuzco). Drawing by Clara Yáñez. 
Aparentemente había también otros temas o conjuntos narrativos, que tendrían que ver con los relatos de la expansión del Tawantinsuyu, en los que igualmente pueden encontrarse diversos soportes vinculados por la representación de un mismo tema central. Uno especialmente claro es el de las guerras contra los antis, sobre las que contamos con textos orales recogidos en las crónicas, con textos visuales plasmados profusamente en muchos queros del período Colonial, y con textos dramáticos, especialmente bailes y cantos, los que también tuvieron a su vez una fuerte representación en los queros, tal vez remarcando su importancia temática (Figura 4).

Pero hay también algunos temas o conjuntos narrativos coloniales en los que las relaciones parecieran ampliarse, abarcando diversos tipos de soportes dramáticos: el caso del ciclo de la Muerte de Atahualpa es uno de ellos, tal vez el más representativo por la cantidad de estudios que ha suscitado (entre otros, véase Burga 2005; Beyersdorff 1998; Husson 1998; López Baralt 1993; Millones 1992; Wachtel 1971). Quisiera referirme aquí únicamente a sus formas de circulación y no a su estructura y contenidos, que han sido abordados profusamente. Se trata de un ciclo que puede encontrarse dentro de una narrativa específicamente oral, la que ha sido denominada contemporáneamente como el "ciclo de Inkarrî́"13 y que se encuentra con una amplia dispersión por diferentes lugares de los Andes, hasta el extremo sur de Chile. Aun cuando hay una polémica respecto de las fechas de origen de este ciclo narrativo ${ }^{14}$, algunos autores como Husson (1998) han postulado que al menos algunos fragmentos del mismo pueden ser identificados para el período Colonial, aunque no sean del mismo siglo XVI.

Tal vez la representación visual más temprana que se conoce de este ciclo sea la de Guaman Poma, que en varias de sus láminas (Figura 5) representa diversos momentos del ciclo: los embajadores que intentan determinar las intenciones de los españoles (fojas 375 y 379); el encuentro entre el Inca y Pizarro (fojas 382 y 384); la prisión de Atahualpa (foja 387); y, finalmente, su muerte por decapitación (foja 390).

Sin embargo, el soporte más conocido y estudiado de este ciclo es el dramático. Más allá del debate acerca de si efectivamente se representó o no en 1555 como lo relata Arzáns de Orzúa y Vela (1965 [1735]:95 y ss ), lo que queda fuera de la discusión es que efectivamente contamos con descripciones coloniales de su realización al menos desde 1659, en la ciudad de Lima (Flores Galindo 1987:67-68), e incluso en los momentos previos a las rebeliones tupamaristas, en Oruro (Beyersdorff 1998 ). Ya en el siglo XVIII, dando

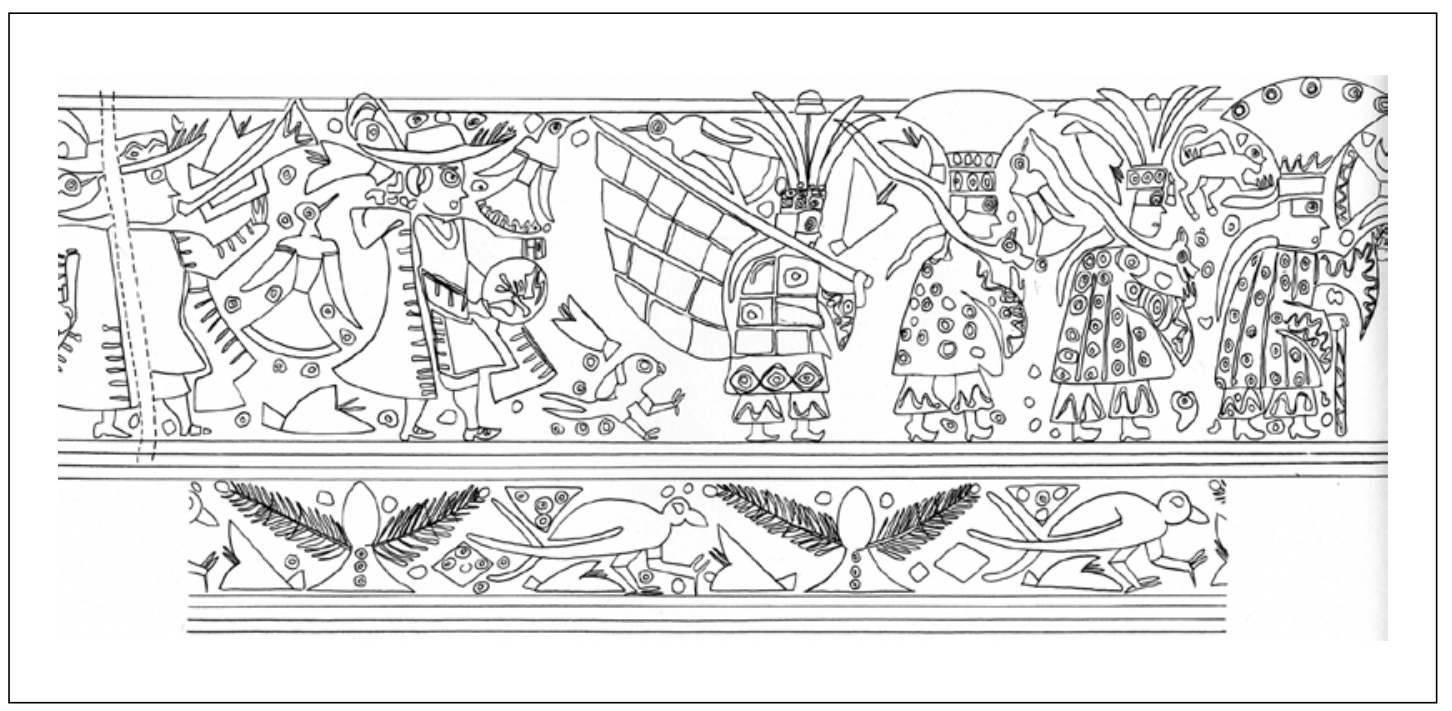

Figura 4. Kero colonial con bailarines vestidos de antis y músicos. Kero Momac 291, perteneciente al Museo Inka (Cusco). Dibujo de Clara Yáñez.

Colonial kero with dancers dressed like Antis, and musicians. Kero Momac 291, Museo Inka collection (Cuzco). Drawing by Clara Yáñez. 


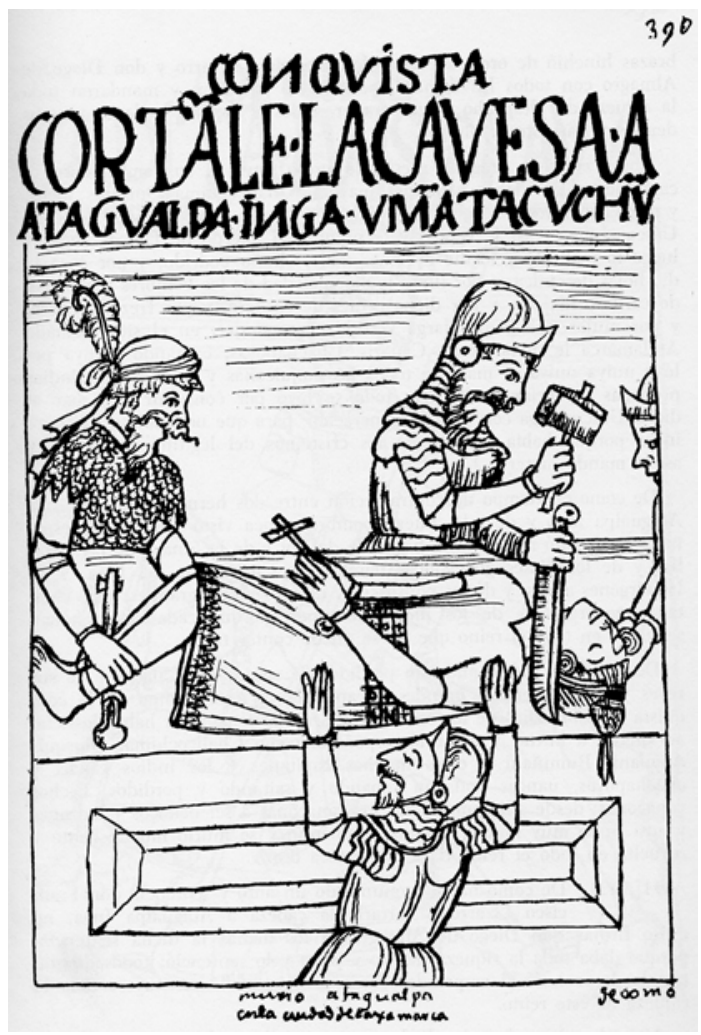

Figura 5. "Murió Atahualpa en la ciudad de Cajamarca". En esta escena se representa el momento en que el inca es degollado por sus verdugos españoles. En Guaman Poma 1980 [1616]:23.

"Atahualpa's death in city of Cajamarca". In this picture, Guaman Poma draw the moment at wich the Inca was beheaded by Spanish executioners. In Guaman Poma 1980 [1616]:283.

muestras de su vitalidad y expansión geográfica, fue pintado, en dos láminas, dentro del conjunto de acuarelas que mandó hacer el Obispo de Trujillo, Martínez Compañón (1978 [1794], véanse sus láminas 172 y ss.), lo que sugiere que también se representaba en esa área.

Uno de los elementos interesantes de esas pinturas es que el referente para hacerlas fue, precisamente, el de su ejecución en público, puesto que el o los pintores anónimos representaron dos momentos centrales de la versión dramatizada: el episodio del sueño y de la adivinación por parte de los sacerdotes andinos (lámina 172) y el de la muerte del Inca por degüello (lámina 173), la que difiere de la versión oficial, histórica, sobre la forma en la cual murió Atawallpa. Más aún, ambas láminas llevan por título explícitamente el de "Danza de la degollación del inca" (Figura 6).

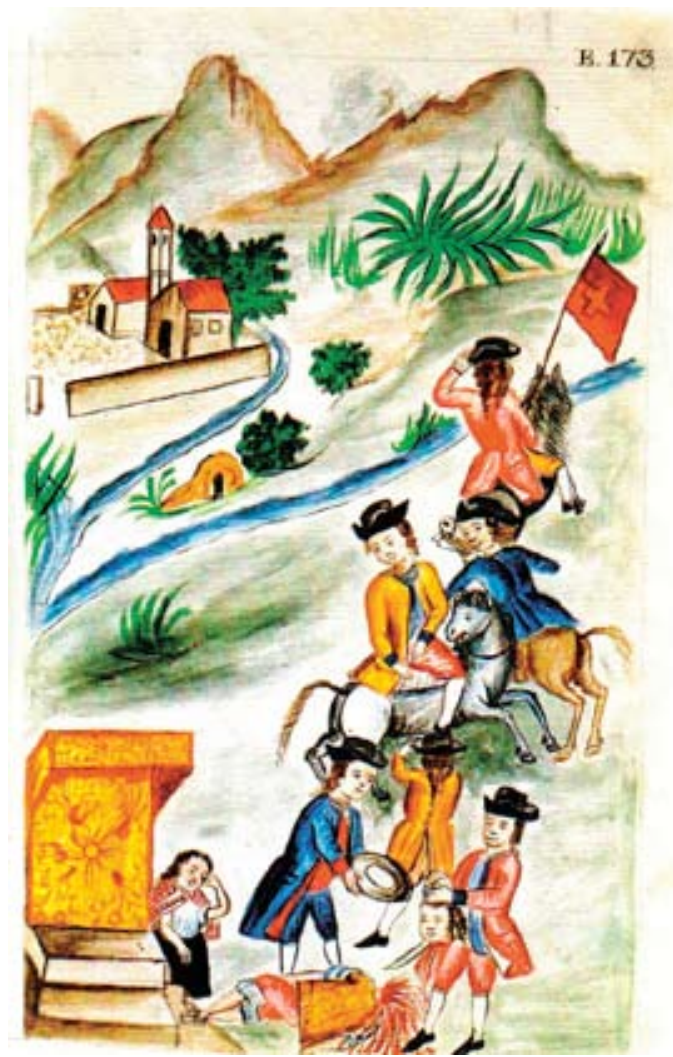

Figura 6. "Danza de la degollación del inca" en el Obispado de Trujillo (costa norte de Perú). Martínez Compañón (1978 [1794]: lámina 173).

"Dance of Inca Decapitation" in the Bishopric of Trujillo (north coast of Peru) in Martínez Compañón (1978 [1794]: plate 173).

Lo que me parece que debe ser destacado es que el tema representado no formaba parte del plan evangelizador colonial. Era un tema más propiamente andino colonial, ya que proponía incluso versiones diferentes a la oficial, al menos sobre la forma de la muerte del Inca ${ }^{15}$.

Estamos en presencia, nuevamente, del mismo tipo de prácticas descritas en la primera parte de este trabajo, que permitían la circulación de ciertos temas socialmente importantes. El tema de la invasión española a los Andes y de la destrucción de las sociedades prehispánicas, sintetizado en la imagen de la muerte del Inca, circulaba -como antaño- a través de diversos soportes, tanto orales como visuales y dramáticos.

Así, aun con cambios, este tipo de prácticas y sistemas permitieron a las poblaciones andinas hacer circular de manera alternativa a la hege- 
monía de la letra escrita, sus propias reflexiones y temáticas.

Agradecimientos: Este trabajo es resultado del proyecto FONDECYT 1061279 "La lucha por el control de la memoria: Escritura, oralidad e imágenes en los Andes de los siglos XVI y XVII". Los comentarios de los evaluadores, así como los de mis colegas y colaboradores en el equipo del proyecto, me permitieron profundizar y aclarar algunas de las ideas expuestas en este trabajo. A todos ellos mi reconocimiento.

\section{Referencias Citadas}

Abercrombie, Th.

2006 Caminos de la Memoria y del Poder. Etnografía e Historia en una Comunidad Andina. IFEA-Instituto de Estudios Bolivianos-ASDI, La Paz.

Adorno, R.

1984 Paradigmas perdidos: Guamán Poma examina la sociedad española colonial. Chungara 13:67-91.

Arzans de Orsúa y Vela, B.

1965 [1735] Historia de la Villa Imperial de Potosí. Edición y estudio preliminar de Lewis Hanke y Gunnar Mendoza. Brown University Press, Providence.

Berenguer, J. y J.L. Martínez

1989 Camelids in the Andes: rock art environment and myths. En: Animals into Art, editado por H. Morphy, pp. 390-416. Unwin Hyman, London.

Beyersdorff, M.

1998 Historia y Drama Ritual en los Andes Bolivianos. Plural-UMSA, La Paz.

Burga, M.

2005 [1998] Nacimiento de una Utopía. Muerte y Resurrección de los Incas. Universidad Nacional Mayor de San MarcosUniversidad de Guadalajara, segunda edición corregida, Lima.

Cabello Carro, $\mathrm{P}$

2006 Continuidad prehispánica y mestizaje en Perú. Una historia de conquistadores narrada en un vaso de libaciones incaico. Anales del Museo de América 14:145-174, Madrid.

Chávez Ballón, $M$.

1964 El Qero cuzqueño. Supervivencia y renacimiento del arte incaico en la colonia. Cultura y Pueblo 2:26-29. Publicación de la Comisión Nacional de Cultura, Lima.

Cruz, P.

2008 La articulación entre la arqueología y la antropología en el pasado prehispánico de Potosí. Ponencia presentada en el Simposio La Etnohistoria: fronteras transdisciplinarias en la producción del conocimiento; ANB- ASUR- Universidad de Nuevo México, Sucre-Bolivia.

Cruz, P., P. Absi y S. Fidel

2005 ¿Y dónde estaban los indios? Potosí antes de la llegada de los españoles. Anuario del Archivo y Biblioteca Nacionales de Bolivia 11:75-101.

Cummins, Th.

1988 Abstraction to Narration: Kero Imagery of Peru and the Colonial Alteration of Native Identity. Ph.D. Dissertation, California University, Los Angeles.

1993 La representación en el siglo XVI: la imagen colonial del inca. En Mito y Simbolismo en los Andes. La Figura y la Palabra, editado por H. Urbano, pp. 87-136. CERA Bartolomé de las Casas, Cusco.

2004 Brindis con el Inca. La Abstracción Andina y las Imágenes Coloniales de los Queros. Universidad Nacional Mayor de San Marcos-Universidad Mayor de San Andrés-Embajada de los Estados Unidos de América, Lima.

Estenssoro, J. C.

1992 Los bailes de los indios y el proyecto colonial. Revista Andina 10(2):353-404.

2003 Del Paganismo a la Santidad. La Incorporación de los Indios del Perú al Catolicismo, 1532-1750. Pontificia Universidad Católica del Perú-Instituto Francés de Estudios Andinos, Lima.

Flores Galindo, A.

1987 Buscando un Inca: Identidad y Utopía en los Andes. Instituto de Apoyo Agrario, Lima.

Flores Ochoa, J., E. Kuon y R. Samanez

1998 Qeros. Arte inka en vasos ceremoniales. Banco de Crédito del Perú, Lima.

Garcilaso de la Vega, I.

1962 [1617] Historia General del Perú. Estudio preliminar y notas de José Durand, Biblioteca de Cultura Peruana, serie histórica 9, Universidad Nacional Mayor de San Marcos, Lima.

1991 [1609] Comentarios Reales de los Incas. Edición, índice analítico y glosario de Carlos Araníbar; Fondo de Cultura Económica, México.

Gisbert, T.

1999 El Paraíso de los Pájaros Parlantes. La Imagen del Otro en la Cultura Andina. Plural-Universidad de Nuestra Señora de La Paz, La Paz.

González Holguín, D.

1989 [1608] Vocabulario de la lengua general de todo el Perú llamada lengua qquichua o del inca... Ed. Facsimilar de la de 1952. Universidad Nacional Mayor de San Marcos, Lima.

Guaman Poma de Ayala, F.

1980 [1616] Nueva Corónica y Buen Gobierno. Edición a cargo de Franklin Pease, Biblioteca Ayacucho, Caracas.

Husson, J-Ph.

1998 En busca del foco de las representaciones de la muerte de Atawallpa: algunos argumentos a favor del estado neoinca de Vilcabamba. Nuevos Comentarios $\mathrm{N}^{\circ}$ 6: 50-81.

Levillier, R.

1940 Don Francisco de Toledo. Supremo Organizador del Perú. Su Vida, su Obra. Colección de Publicaciones Históricas de la Biblioteca del Congreso Argentino, Imprenta Porter Hnos., Buenos Aires. 
López-Baralt, M.

1993 Guaman Poma, Autor y Artista. Pontificia Universidad Católica del Perú, Lima.

Martínez Compañón, B.

1978 [1794] Trujillo del Perú. Ediciones Cultura Hispánica del Centro Iberoamericano de Cooperación, Madrid.

Millones, L.

1992 Actores de Altura. Ensayos sobre el Teatro Popular Andino. Ed. Horizonte, Lima.

Molina, C. de (el Cuzqueño)

1989 [1575] Relación de las fábulas y ritos de los Incas. En Fábulas y Mitos de los Incas. Edición de H. Urbano y P. Duviols, pp. 4 7-134; Historia 16, Madrid.

Mulvany, E.

2004 Motivos de flores en keros coloniales: imagen y significado. Chungara Revista de Antropología Chilena 36:407-419.

Murra, J.

1978 La correspondencia entre un 'capitán de mita' y su apoderado en Potosí. Historia y Cultura 3:45-58.

1980 Waman Puma, etnógrafo del mundo andino. En Guaman Poma de Ayala, F.: El primer Nueva Corónica y Buen Gobierno: xiii-xix. Siglo XXI Eds., México.

2002 El Mundo Andino. Población, Medio Ambiente y Economía. Instituto de Estudios Peruanos-Pontificia Universidad Católica del Perú, Lima.

Ossio, J.

1973 Ideología Mesiánica del Mundo Andino (Antología). Ed. de Ignacio Prado, Lima.
Rostworowski, M.

2001 [1952] Pachacutec. En Obras Completas, vol. I, I.E.P., Lima.

Salomon, F.

2006 Los Quipocamayos. El Antiguo Arte del Khipu en una Comunidad Campesina Moderna. IFEA-IEP, Lima.

Sandron, M.

1999 Un intento de lectura pictográfica e ideográfica de unos queros coloniales del Museo de América. Anales del Museo de América 7:141-155, Madrid.

Silverman-Proust, G.

1986 Representación gráfica del mito Inkarrí en los tejidos Q'ero. Boletín del Museo de Lima 48:59-71.

Taylor, G.

1987 Ritos y tradiciones de Huarochiri. Manuscrito quechua de comienzos del siglo XVII. Versión paleográfica, interpretación fonológica y traducción al castellano de...; I.E.P.- I.F.E.A., Lima.

Wachtel, N.

1971 La Vision des Vaincus. Les Indiens du Perou devant la Conquête Espagnole. Éditions Gallimard, Paris.

Wichrowska, O. y M. Ziólkowski

2000 Iconografía de los Keros. Andes Boletín de la Misión Arqueológica Andina $\mathrm{N}^{\circ}$ 5, Varsovia.

Williams, V.

2006 Símbolos materiales y sistemas de representación del Imperio Inca en el NOA. Ponencia presentada en el $52^{\circ}$ Congreso Internacional de Americanistas, Sevilla.

\section{Notas}

1 En su Introducción a la edición de Guaman Poma: "Waman Puma, etnógrafo del mundo andino" (1980).

2 "La correspondencia entre un 'capitán de mita' y su apoderado en Potosí” (1978, también en 2002).

3 Algunas de esas otras lecturas posibles, desde el cómo se caracterizaba un "hecho" o acontecimiento y cuáles podrían ser los significantes puestos en acción, hasta cómo se plantea la relación entre el relato oral y su expresión visual, pasando por las diferentes articulaciones de algunas categorías conceptuales que podrían organizar la expresión visual rupestre (mitades, desplazamientos espaciales, desdoblamientos, por ejemplo), están siendo desarrolladas en un trabajo en elaboración, que forma parte del Proyecto FONDECYT 1061279.

4 Propongo el concepto de ciclo para dar cuenta de la existencia de variaciones narrativas entre las distintas versiones que circulaban sobre un mismo tema. A modo de ejemplo, estas variaciones son particularmente claras en ciclos como el de la guerra contra los chancas, en el que diversos informantes, autores andinos y cronistas europeos dieron cuenta de versiones que difieren entre sí, desde la época en que se sitúa lo ocurrido (Guaman Poma relata esos eventos como parte de la fundación del Cusco), a los personajes involucrados (la ñusta Chañan Curi Coca o los purum aucas no aparecen en todas las versiones, ni los personajes principales son los mismos), entre otras variantes. La noción de ciclo permite incluir esas variaciones no como "errores" o "distorsiones" respecto de un único relato originario, sino como variantes que pudieran dar cuenta de distintas voces narrativas o enunciadoras.

5 Ritos y Tradiciones de Huarochiri, en adelante RTH, ver Taylor 1987.

6 Molina 1989 [1575]; Véase el análisis de Cummins (1993) al respecto.

7 Véanse, entre otros, los trabajos de Salomon 2006 y de Cummins (1993).

8 También Mulvany (2004:411) asume una relación entre textiles y queros que soportarían contenidos temáticos similares.

9 Verónica Williams, ponencia presentada en el $52^{\circ}$ Congreso Internacional de Americanistas, Sevilla, 2006.

10 Rostworowski (2001:104-119) ha hecho una muy buena discusión y síntesis de las diferencias entre las varias versiones conocidas.

11 Véase, por ejemplo Estenssoro (1992 y 2003) y Abercrombie (2006:249).

12 En varios casos se han identificado un conjunto de tocapus en el campo intermedio, que como lo ha señalado Ziólkowski, posiblemente harían referencia a los personajes representados en la escena superior de tipo figurativo, permitiendo la identificación de algunos de ellos. Ziólkowski, ponencia presentada en el $52^{\circ}$ Congreso Internacional de Americanistas, Sevilla, 2006.

13 Véase la compilación hecha por Juan Ossio, en la que se incorporan, entre otros, los trabajos de Arguedas, Roel y 
otros estudiosos del tema, Ossio 1973; Beyersdorff 1998; Millones 1992:34 y ss., entre otros.

14 El más destacado crítico de Arzáns al respecto es Burga (2005 [1988]). Recientemente el arqueólogo Pablo Cruz (Cruz et al. 2005; Cruz 2008) ha aportado nuevas evidencias arqueológicas que muestran que en los alrededores del cerro de Potosí había importantes asentamientos cuzqueños, no descartando la presencia de un gran número de miembros de la élite gobernante cuzqueña, la que se habría trasladado posteriormente a la recién fundada ciudad de Potosí. Esto permitiría rebatir el cuestionamiento de Burga ((2005 [1998]:408 y ss.), que se sustenta en su incredulidad acerca de una presencia cuzqueña relevante, realizando dramatizaciones de temas incaicos en un entorno colonial regional tan distante del Cusco.

15 El carácter andino y no europeo de muchas de las versiones del ciclo sobre Atahualpa-Inkarri, ha sido destacado también por Silverman-Proust (1986), quien muestra que los diferentes motivos tejidos en la comunidad de Q'ero, que representan diversas etapas del mito de Inkarri, enfatizan el tema de la cabeza cortada. La autora propone que una estructura similar de circulación de ciclos míticos a través de distintos sistemas de soportes también funcionaría actualmente, en la misma localidad de Q'ero (Silverman-Proust (1986:71). 
